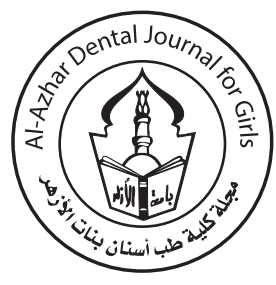

\title{
Remineralization of Early Carious Lesion Using Natural Agents Versus Bioadhesive Polymers
}

\author{
Marwa M. Abd el-monem ${ }^{1 *}$, Maha A. Niazy ${ }^{2}$, Mohamed A. El-Yassaky ${ }^{3}$.
}

Codex : 03/21.10

azhardentj@azhar.edu.eg

http://adjg.journals.ekb.eg

DOI: 10.21608/adjg.2021.36878.1279

Restorative Dentistry

(Removable Prosthodontics, Fixed

Prosthodontics, Endodontics, Dental Biomaterials, Operative Dentistry)

\section{KEYWORDS}

Eggshell nanoparticles,

Bioadhesive polymers, clove,

Microhardness assessment.

\begin{abstract}
Purpose: The study was established to compare the remineralization effect of natural agents versus bioadhesive polymers with or without PH cycling using a microhardness test. Materials and Methods: Forty extracted premolars were used. The roots of the teeth were removed, then the crowns of teeth were cut in mesiodistal direction to expose the labial and lingual portion using a diamond disc so that 80 specimens were obtained. Each tooth-half was fixed with superglue on the custom made acrylic block. The enamel surfaces were polished to produce flat enamel surfaces. 80 specimens were divided into four groups (A) according to the remineralizing agent used. Group A1 for eggshell nanoparticles, Group A2 for clove extract, and Group A3 for carbopol, and Group A4 for carboxymethyl cellulose (20 each). Each group was subdivided into two subgroups (10 each) according to PH cycling either with (B1) or without (B2). Then, the specimens were examined before and after demineralization and after treatment agent with Digital Display Vicker Microhardness Tester. Results: The results showed that the highest microhardness mean values were found with eggshell nanoparticles followed by carbopol, and then carboxymethyle cellulose then clove extract. Conclusion: Natural materials have remineralizing potentials and could successfully replace synthetic products.
\end{abstract}

\section{INTRODUCTION}

Enamel is the outer part of the tooth so it is in contact with the saliva. Calcium hydroxyapatite crystal is one of the components in enamel. Enamel is the strongest tissue, but it is non-vital and if it lost the body cannot replace it. Continuous loss of minerals from the

- Paper extracted from Doctor Thesis Titled" Remineralization of Early Carious Lesion Using Natural Agents Versus Bioadhesive Polymers"

1. Assistant lecturer of operative dentistry, Faculty of Dental Medicine for Girls, Al-Azhar University, Cairo, Egypt

2. Professor of operative dentistry, Faculty of Dental Medicine for Girls, Al-Azhar University, Cairo, Egypt.

3. Professor of operative dentistry, Faculty of Dental Medicine for Girls, Al-Azhar University, Cairo, Egypt.

*Corresponding author email: roromrmr125@gmail.com 
hydroxyapatite structure of the enamel is called demineralization process. When the hydroxyapatite reacts with hydrogen ions at acidic $\mathrm{pH} \leq 5.5$ the demineralization occurs. De-mineralization affects the surface texture so when enamel loses its structure its surface becomes rougher. The appearance of white spot lesions is sign of de-mineralization. It is chalky white appearance on the enamel surface, which is reversible by remineralization ${ }^{(1)}$. The repairing mechanism to restore the hydroxyapatite (HAP) crystal lattice naturally is called the remineralization process. It occurs under physiological $\mathrm{pH}$ conditions whereby calcium and phosphate mineral ions are redepositing from saliva and plaque fluid within the lesion resulting in the formation of newer HAP crystals, which are more resistant to acid dissolution $^{(2)}$.

Fluoride is responsible for the decrease of caries due to its cariostatic properties. However when it comes to its effect in inhibiting caries progression, it has certain limitations. When fluoride is increased in concentration, it can produce harmful effects to the tooth ${ }^{(3)}$.

Chicken eggshell powder (CESP) is rich by mineral salts, mostly calcium carbonate. Its components are $98 \% \mathrm{CaCO}_{3}, 1 \%$ phosphate and $1 \%$ magnesium. It is the best natural source of calcium. So the clinical studies found that the CESP can be used in remineralization of teeth structure ${ }^{(4)}$.

Clove is the dried flower buds of a tree. It is used for many purposes because its health benefits, as a food preservative, flavoring agent in food, dental preparations. It has a role as an anti-cariogenic agent and in the treatment of toothache and fight bad breath. Besides all that, there are previous studies regarding the effect of water clove extract on the remineralization of enamel surface ${ }^{(5)}$.

Bioadhesive polymers are widely used in biomedical fields because they have improved properties. Polymers have an important role in dentistry, such as restorative, regenerative and preventive therapies. The polymers are preventing the teeth from demineralization by protecting them from acid contact in the oral cavity ${ }^{(6)}$.

Thus the purpose of present study was to evaluate the remineralizing potential of natural agents (eggshell powder and clove water extract) versus bioadhesive polymers (carbopol and carboxymethyl cellulose). The null hypothesis of this study is that there is no difference between natural agents and bioadhesive polymers as remineralizing materials in early carious lesions in enamel of teeth.

\section{MATERIALS AND METHODS}

Four treatment agents were used: Eggshell nanoparticles, Clove water extract, Carbopol, and Carboxymethyle cellulose.

\section{Teeth selection:}

A total of forty freshly extracted young upper or lower premolars were used. Teeth were extracted from patients ranging from 14 to 20 years, for orthodontic purposes and the patients were consented to the use of their teeth. Teeth were obtained from the orthodontic clinic, Faculty of Dentistry, AlAzhar University. The study was approved by the "Ethical Research committee" of faculty of Dental Medicine for girls; Al-Azhar University, Cairo, Egypt (protocol number REC17-030). Then teeth were washed with water to remove the blood and scraped with scaler to remove attached periodontal tissue, plaque, and calculus, then stored in distilled water and used within one month. Teeth with surface defects, decay, cracks, or restoration, were discarded ${ }^{(7)}$.

\section{Sample grouping:}

A total of 80 specimens were divided into four groups (20 each) according to the remineralizing agent used (A). Group A1 for eggshell powder, Group A2 for clove extract, Group A3 for carbopol, and Group A4 for carboxymethyl cellulose. Each group was subdivided into two subgroups (10 each) according to $\mathrm{PH}$ cycling either with (B1) or without (B2). 


\section{Teeth preparation:}

The roots were removed from the teeth. Then, the crowns were cut in mesiodistal direction to expose the labial and lingual portions using a diamond disc so that 80 specimens were obtained from a total of 40 teeth. Custom made plastic cylindrical molds were made. Then, the molds were filled by self-cured acrylic resin. Each tooth-half was fixed with superglue on the custom made acrylic block so that the buccal and lingual side of each was available. Using abrasive paper discs (Henan Tianze Imp. and Exp.) from 600 grit up to 1200 grit under water irrigation flat enamel surfaces were obtained. Experimental windows were created on the enamel surface of the samples (dimension of $4 \mathrm{~mm} \times 5 \mathrm{~mm}$ ) using French manicure tip guides and the remaining sample surfaces were made completely resistant to acid attack by coating nail polish ${ }^{(8-10)}$.

\section{Preparation of materials:}

\section{A. Preparation of Chicken Eggshell Powder (CESP):}

Twenty chicken eggs were collected, the contents of eggs were removed and distilled water was used to clean the eggshells. Then the egg shells were left in a hot water bath for 10 minutes then removing the inside membrane. A kitchen grinder was used to form a coarse powder from the dried shells. Ball milling machine was used for milling the dried powder for $10 \mathrm{~h}$, at a speed of $350 \mathrm{rpm}$, and $3 \mathrm{~min}$ intervals to obtain Nano-sized ESP ${ }^{(11)}$.

\section{Characterizations}

Size \& Shape: (Figure 1)

Nano-ESP were examined by transmission electron microscopy (TEM) operating at $200 \mathrm{kV}$ equipped with Gatan digital camera Erlangshen ES500. average size was less than $20 \mathrm{~nm}$.

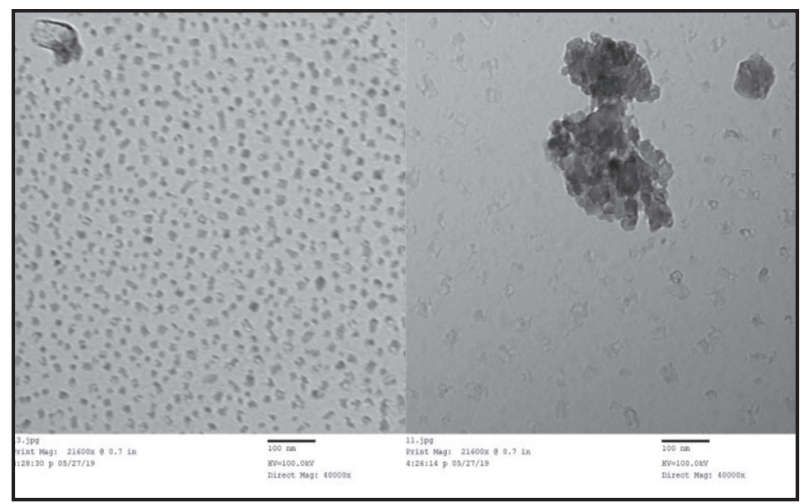

Figure(1) TEM images of the Eggshells nanoparticles

\section{B. Preparation of clove water extract:}

Clove was ground into fine powder in an electrical mixer. 100 grams of finely powdered clove were mixed with one liter of deionized water and left in a water bath for 5 hours. Then, the powder was filtered by filter paper. Then, the extract was left to dry in hot air oven for evaporation of water. Until using the extract it was kept into a refrigerator ${ }^{(12)}$.

\section{Preparation of The Gel form from the treatment materials:}

The treatment material was obtained then dispersed in distilled water by $10 \% \mathrm{w} / \mathrm{v}$ with stirring and then gradually adding polyethylene oxide $(\mathrm{MW}=60,000) \% \mathrm{w} / \mathrm{v}$ to the suspension to get the treatment materials in gel form ${ }^{(13)}$.

\section{Demineralization of enamel:}

The samples were then demineralized in $25 \mathrm{ml}$ $0.3 \%$ citric acid at a $\mathrm{PH}$ of 3.25 . This $\mathrm{pH}$ was reached by the gradual addition of $\mathrm{NaOH}$ to the citric acid using a pipette. PH was measured and kept constant using a $\mathrm{pH}$ meter. Each sample was immersed in the acid for 3minutes. Immediately afterward, all samples were carefully washed by water to remove any excess of $\operatorname{acid}^{(8,9)}$. 


\section{Application of treatment agents:}

The treatment agents were applied once onto the enamel samples. An insulin syringe $(1 \mathrm{ml})$ was used to standardize the quantity applied on the enamel surface, the treatment agents were brushed using a micro brush for $20 \mathrm{sec}$, left for $10 \mathrm{~min}$ and then rinsed with distilled water ${ }^{(14)}$.

\section{PH Cycling:}

Each group was subdivided into two subgroups one of them was subjected to PH- cycling and the other subgroup was immersed in artificial saliva. Initially, the samples were kept in $150 \mathrm{~mL}$ of remineralization solution for 24 hours. The samples were exposed to a 9 days $\mathrm{pH}$ cycling in the form of $24 \mathrm{~h}$ periods ${ }^{(15)}$. First, samples were left in $20 \mathrm{ml}$ of demineralization solution arranged with $4.3 \mathrm{pH}$ which included $1.5 \mathrm{mM} \mathrm{CaCl}, 0.9 \mathrm{mM} \mathrm{KH}_{2} \mathrm{PO}_{4}$ and $50 \mathrm{mM}$ acetic acid at $37.5^{\circ} \mathrm{C}$. Then these samples were removed from this solution and washed with distilled water. Samples were left in $20 \mathrm{ml}$ of remineralization solution with $7 \mathrm{pH}$ value which consisted of $1.5 \mathrm{mM} \mathrm{CaCl}, 5 \mathrm{mM} \mathrm{KH}_{2} \mathrm{PO}_{4}$ and $100 \mathrm{mM}$ acetic acid for the next $17.5 \mathrm{~h}$ at $37.5^{\circ} \mathrm{C}$. Then, the samples were extracted from the solution and washed with distilled water then placed again in distilled water. These solutions were made fresh and changed daily ${ }^{(16)}$.

\section{Surface Microhardness Assessment (SMH):}

All samples were subjected to microhardness assessment at baseline, after demineralization and after all steps of treatment during the test procedures. Surface microhardness was evaluated by Digital Display Vicker Microhardness Tester with a Vicker diamond indenter and a 20X objective lens. 100g of load was applied on the enamel surface for 10 seconds ${ }^{(17)}$.

\section{RESULTS}

Data were explored for normality using the Kolmogorov-Smirnov test of normality. The results of the Kolmogorov-Smirnov test indicated that most of the data were normally distributed (parametric data), so parametric tests were used.

One way analysis of variance (ANOVA) test was used to compare between the different intervals within the same group, followed by Tukey's post hoc test when the difference was found to be significant. An unpaired t-test was used for comparison between 2 independent groups. The significance level was set at $\mathrm{p} \leq 0.05$. Statistical analysis was performed with SPSS 16.0 (Statistical Package for Scientific Studies, SPSS, Inc., Chicago, IL, USA) for Windows.

Table (1) demonstrated Mean and standard deviation (SD) of microhardness (VHN) for groups at baseline, after demineralization and after using the different tested materials with and without application of PH cycling. Results revealed that eggshell nanoparticles (A1) with PH cycling, there was a statistically significant difference between baseline mean values and both the demineralization and remineralized enamel $(\mathrm{P}=0.027)$, While $\mathrm{A} 1$ without $\mathrm{PH}$ cycling demonstrated a statistically nonsignificant difference in microhardness mean values between remineralized, demineralized and baseline enamel. While results of Clove water extract (A2) with $\mathrm{PH}$ cycling, there was a statistically nonsignificant difference in microhardness mean values between remineralized, demineralized, and baseline enamel. Similarly, results of A2 without PH cycling, there was a statistically non-significant difference in microhardness mean values between remineralized, demineralized and baseline enamel. While Results revealed that Carbopol (A3) with $\mathrm{PH}$ cycling, there was a statistically significant difference between baseline mean values and both the demineralized and remineralized enamel $(\mathrm{P}=0.004)$. Results revealed that $\mathrm{A} 3$ without $\mathrm{PH}$ cycling, there was a statistically significant difference between baseline mean values and demineralized enamel microhardness mean values $(\mathrm{P}=0.03)$. There was a statistically significant difference between both remineralized and demineralized, and non- statistical significance with baseline enamel microhardness. While 
Results revealed that Carboxymethele cellulose (A4) with PH cycling, there was a statistically significant difference between baseline mean values and demineralized enamel microhardness mean values $(\mathrm{P}=0.045)$. There was a statistically significant difference between both remineralized and demineralized and non- statistical significance with baseline enamel microhardness. While results revealed that A4 without $\mathrm{PH}$ cycling, there was a statistically significant difference between baseline mean values and both the demineralized and remineralized enamel $(\mathrm{P}=0.003)$.

Table (1): Statistical analysis comparing all type of materials with and without application of PH cycling on the microhardness of enamel

\begin{tabular}{ccccc}
\hline \multirow{2}{*}{ Materials } & \multicolumn{3}{c}{ Microhardness (Mean \pm SD) } \\
\cline { 2 - 4 } & Baseline & Demineralized & Remineralized & P-Value \\
\hline A1 with PH cycle & $293.67^{\mathrm{a}} \pm 29.16$ & $235^{\mathrm{b}} \pm 22.91$ & $273.4^{\mathrm{c}} \pm 17.2$ & $0.027^{*}$ \\
\hline A1 without PH cycle & $283.67 \pm 34.21$ & $232.33 \pm 46.80$ & $269.67 \pm 29.50$ & $0.297 \mathrm{NS}$ \\
\hline A2 with PH cycle & $270.20 \pm 33.1$ & $246.7 \pm 35.6$ & $226.40 \pm 15.9$ & $0.121 \mathrm{NS}$ \\
\hline A2 without PH cycle & $295.67 \pm 21.39$ & $243.67 \pm 37.85$ & $218 \pm 35.76$ & $0.065 \mathrm{NS}$ \\
\hline A3 with PH cycle & $312^{\mathrm{a}} \pm 8.98$ & $275^{\mathrm{b}} \pm 13.49$ & $286.68^{\mathrm{c}} \pm 11.29$ & $0.004^{*}$ \\
\hline A3 without PH cycle & $310.67^{\mathrm{a}} \pm 12.10$ & $247.33^{\mathrm{b}} \pm 15.04$ & $272^{\mathrm{a}} \pm 12.49$ & $0.03^{*}$ \\
\hline A4 with PH cycle & $310^{\mathrm{a}} \pm 31.22$ & $231^{\mathrm{b}} \pm 32.91$ & $257^{\mathrm{a}} \pm 24.88$ & $0.045^{*}$ \\
\hline A4 without PH cycle & $292.67^{\mathrm{a}} \pm 25.11$ & $231^{\mathrm{b}} \pm 20.30$ & $252.33^{\mathrm{c}} \pm 17.79$ & $0.003^{*}$ \\
\hline
\end{tabular}

* = significant, $N S=$ Non- significant

Tukey's post hoc test: mean value with different letters within each row indicates a significant difference at $P \leq 0.05$. Without letters indicates statistically non-significant

Table (2) and figure (2) demonstrated the percentage of enamel microhardness recovery within each group of materials. Enamel group treated by Eggshell nanoparticles with PH cycling showed the highest percentage of recovery $(70.33 \pm 17.04)$, followed by eggshell nanoparticles without $\mathrm{PH}$ cycle $(57.33 \pm 34.08)$, then carbopol with $\mathrm{PH}$ cycle (45.33 \pm 25.81$)$, carbopol without $\mathrm{PH}$ cycle (39.67 \pm 11.68$)$, carboxymethyl cellulose with $\mathrm{PH}$ cycle $(39.00 \pm 19.47)$, followed by carboxymethyl cellulose without $\mathrm{PH}$ cycle $(35.67 \pm 16.01)$ with statistical insignificance between groups. The clove water extract group showed the lowest percentage of recovery with the $\mathrm{PH}$ cycle $(-19.76 \pm 9.68)$ and without the PH cycle $(-21.67 \pm 10.41)$ with statistical non-significance between both groups and statistically significant difference between this group and all other groups $(\mathrm{p}=0.003)$.
Table (2): Percentage of enamel microhardness recovery within each group of materials

\begin{tabular}{|ccc|c|}
\hline Materials & Microhardness & Rank & P-value \\
\hline $\begin{array}{c}\text { Eggshell with PH cycling } \\
\text { Eggshell without PH } \\
\text { cycling }\end{array}$ & $70.33 \pm 17.04$ & $\mathrm{a}$ & \\
\hline $\begin{array}{c}\text { Clove with PH cycling } \\
\text { Clove without PH cycling }\end{array}$ & $-19.76 \pm 9.68$ & $\mathrm{~b}$ & \\
\hline $\begin{array}{c}\text { Carbopol with PH cycling } \\
\text { Carbopol without PH } \\
\text { cycling }\end{array}$ & $-21.67 \pm 10.41$ & $\mathrm{~b}$ & \multirow{2}{*}{$0.003^{*}$} \\
\hline CMC with PH cycling & $39.00 \pm 25.81$ & $\mathrm{a}$ & \\
\hline CMC without PH cycling & $35.67 \pm 16.01$ & $\mathrm{a}$ & \\
\hline
\end{tabular}

$*=$ significant, $N S=$ Non- significant

Tukey's post hoc test: mean value with different letters within each row indicates a significant difference at $P \leq 0.05$. Without letters indicates statistically nonsignificant 


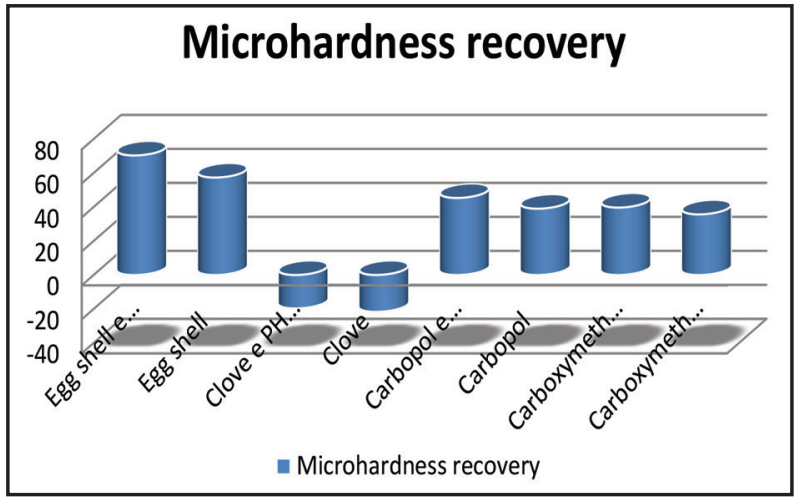

Figure (2) Bar chart showing the percentage of enamel microhardness recovery within each group of materials

\section{DISCUSSION}

The hard dental tissue is continuously undergoing cycles of de-mineralization and re-mineralization. The progression of caries occurred when the demineralization exceeds remineralization. The remineralization is forming calcium, phosphate and fluoride ions from an external source to the demineralized enamel in the tooth surface. Re-mineralization is happen when calcium and phosphate presence in the saliva among the enamel or dentine crystals re-crystalize so the enamel and dentin become resistant to acids than the original one. The studies attempt to prevent early carious disease from progression and improve function, strength and aesthetics by the re-mineralization ${ }^{(18)}$.

The tooth substrate that was selected for this study was enamel rather than dentin because the enamel is the first line of defense against caries progression. Although enamel is a hard and dense material, it possesses local differences in porosity and acid solubility; acids can penetrate deep into the enamel and dissolve tooth minerals locally, rather than dissolving the enamel layer by layer. Therefore, remineralization of early enamel lesions is of great value to protect other dental tissues ${ }^{(19)}$.

Assessment of enamel remineralization in this study was performed by studying the Surface Microhardness $(\mathrm{SMH})$ of the specimens. It is a simple technique for evaluating the de-mineralization and re-mineralization process. This technique is popular because it allows hardness determination in the same sample before and after the treatments which decrease the experimental error ${ }^{(20)}$.

Based on the results of this study, the microhardness of samples decreased after immersion in the demineralizing agent. This finding is consistent with other studies. This was an indication of the demineralization of the enamel surface. This reduction in SMH values coincides with other studies that reported that initial enamel lesions with intact surfaces recorded low mineral content when compared to sound enamel; thus, demonstrating a lower microhardness value at the surface than for sound enamel tissue ${ }^{(21)}$.

In this study, the Eggshell powder (CESP) group exhibited the statistically significant highest mean value of microhardness after PH cycling followed by those samples without PH cycling (without any significant difference) compared with other groups. This may be due to the incorporation of CESP with calcium. It contains calcium carbonate, phosphate and magnesium ${ }^{(22,23)}$. The microhardness mean values were higher after $\mathrm{PH}$ cycling because this higher $\mathrm{pH}$ is favorable for the increased ionic activity of anions such as $\mathrm{oH}^{-1}$ ions and $\mathrm{Po}_{4}^{-3}$ ions. Thus more ions are available for enamel surface re-mineralization. If the $\mathrm{pH}$ of re-mineralizing solution is acidic, thus the concentration of $\mathrm{H}^{+}$ions is increased which combines with the available anions and thus fewer ions will be available for remineralization ${ }^{(24)}$.

However, these results are not consistent with a study that compared the effect of CESP with commercially available Sensodyne Pronamel. This could be attributed to material difference as these studies used other fluoride-containing products ${ }^{(25)}$.

On the other hand, results revealed that Carbopol with and without $\mathrm{PH}$ cycling recorded the 
highest significant mean value of microhardness as compared to CESP. This was followed by the mean microhardness values of carboxymethyle cellulose (CMC) with and without PH cycling. Carbopol is a polymer with a high molecular weight of polyacrylic acid; it formed a bond with $\mathrm{Ca}^{++}$in the enamel, thus making a layer that protected the enamel against demineralization. However, Carboxymethyle cellulose can decrease the demineralization like the artificial saliva. The mechanism of this effect may be due to the film formation. The weak bond between Carboxymethyle cellulose and the hydroxyapatite may be responsible for reduction in the remineralizing effect of saliva, which acted as a barrier hampering the re-mineralizing action of saliva ${ }^{(26)}$.

The results of this study showed that clove water extract provided less re-mineralization than other groups and an insignificant mean value of microhardness with and without PH cycling. It was shown that the clove extract has many elements other than $\mathrm{Ca}$ like manganese which might substitute $\mathrm{Ca}$ ion of hydroxyapatite crystals leading to a decrease in the $\mathrm{Ca} / \mathrm{P}$ ratio and could form other crystals that may reduce the microhardness of tooth structure. This might explain the decreased enamel microhardness value with increase in clove extract concentrations more than $5 \%{ }^{(27)}$.

The Percentage of enamel microhardness recovery was insignificant after using of CESP, carbopol and CMC on the enamel, that may be due to diffusion the mineral ions into the superficial layer obstruct the surface porosities; further this diffusion of minerals is limited after reaching a plateau. However, there was a significant decrease in microhardness of enamel after using of clove water extract because it has a less microhardness values on enamel ${ }^{(28)}$. Thus, null hypothesis is rejected as there is difference between natural agents and bioadhesive polymers as remineralizing materials in early carious lesions in enamel of teeth.

\section{CONCLUSIONS}

From the study, it could be concluded that:

Egg shell nanoparticles seemed to have remineralizing potentials and could successfully replace synthetic products. Though, clove water extract was not reliable as a remineralizing agent for early carious lesion. Carbopol is a promising remineralizing agent.

\section{REFERENCES}

1. Detara M, Triaminingsih S, Irawan B. Effects of nano calcium carbonate and siwak toothpaste on demineralized enamel surface roughness. J Phys Conf Ser. 2018; 1073: $1-7$.

2. Arifa MK, Ephraim R, Rajamani T. Recent Advances in Dental Hard Tissue Remineralization: A Review of Literature. Int J Clin Pediatr Dent 2019; 12: 139-44.

3. Soares R, Noronha I, Fernandes M, Lambor R. Assessment of Enamel Remineralization After Treatment with Four Different Remineralizing Agents: A Scanning Electron Microscopy (SEM) Study. J Clinical and Diagnostic Res. 2017; 4: ZC136-ZC141.

4. Allam G and Abd El-Geleel O. Evaluating the Mechanical Properties, and Calcium and Fluoride Release of GlassIonomer Cement Modified with Chicken Eggshell Powder. Dent J. 2018; 6: 40-8.

5. Elgamily H, Safy R, Makharita R. Influence of Medicinal Plant Extracts on the Growth of Oral Pathogens Streptococcus Mutans and Lactobacillus Acidophilus: An In-Vitro Study. Open Access Maced J Med Sci. 2019; 7: 2328-34.

6. Rokaya D, Srimaneepong V, Sapkota J, Qin J, Siraleartmukul K, Siriwongrungson V. Polymeric materials and films in dentistry: An overview. J Adv Res. 2018; 14: 25-34.

7. Zarem S, Niazy M, Gad N. Effect of Hydroxyapatite and Sodium Hexameta Phosphate

8. Application on Demineralized Enamel and Dentine. ADJfor girls, 2016; 3: 183-91.

9. Abdelaziz R H, Mohamed A, Talaat D M. Effect of two remineralizing agents on microhardness of initial enamel caries like lesions in young permanent teeth. Alex Dent J. 2019; 44: 45-9. 
10. Madhusudanan P, Praveena S V, Pillai R, Varghese NO, George S, Antony A. Comparative Evaluation of Surface Microhardness of Artificially Demineralized Human Enamel with Nano Hydroxyapatite, Calcium Phosphate, and Potassium Nitrate Remineralizing Agents: An In Vitro Study. Cons Dent Endod J. 2019; 3: 50-5.

11. Metwally N, Niazy M, El-Malt M. Remineralization of Early Carious Lesions using Biomimetic Selfassembling Peptides Versus Fluoride agent. (In vitro and In vivo study). ADJ-for girls, 2017; 4: 179-88.

12. El-Shibiny S, Abd El-Gawad M A M, Assem F M, ElSayed S M. The use of nano-sized eggshell powder for calcium fortification of cow's and buffalo's milk yogurts. Acta Sci Pol Technol Aliment. 2018; 17: 37-49.

13. El Ghallab Y, Al Jahid A, Eddine J, Said A, Zarayby L, Derfoufi S. Syzygium aromaticum L: phytochemical investigation and comparison of the scavenging activity of essential oil, extracts and eugenol. ADV TRADIT MED (ADTM). 2020; 20: 153-8.

14. Onaciu A, Munteanu R A, Moldovan A I, Moldovan C S, Berindan-Neagoe I. Hydrogels Based drug delivery synthesis, characterization and administration. Pharmaceutics. 2019; 11: 432-56.

15. Kunam D, Manimaran S, Sampath V, Sekar M. Evaluation of dentinal tubule occlusion and depth of penetration of nano-hydroxyapatite derived from chicken eggshell powder with and without the addition of sodium fluoride: An in vitro study. J Conserv Dent. 2016; 19: 239-44.

16. Ismail S, Niazy M, El-Sharkawy D. Effect of Two Different Collagen Cross Linking Agents versus Topical Fluoride on Management of Root Caries (In Vitro Study). ADJ-for girls, 2017; 4: 161-6.

17. Aras A, Celenk S, Dogan M S, Bardakci E. Comparative evaluation of combined remineralizating agent on demineralized tooth surface. Niger J Clin Pract. 2019; 22: 1546-52.

18. Abdel-Raouf E, Shoreibah E, Elmasry E, Niazy M, Mostafa M. A Clinical and Laboratory Evaluation of Different Remineralizing Agents Used for Treatment of Carious Posterior Teeth. ADJ-for girls, 2016; 3: 215-21.

19. Talwar M, Farahani A B, Lynch E, Borsboom P, Ruben J. Remineralization of Demineralized Enamel and Dentine Using 3 Dentifrices, An InVitro Study. Dent J. 2019; 7: 91-103.
20. Kamh R, Niazy M, El-Yasaky M. Clinical Performance and Remineralization Potential of Different Biomimitic Materials on White Spot Lesions. ADJ-for girls, 2018; 5: 349-58.

21. Soares R, Noronha I, Fernandes M, Lambor R. Assessment of Enamel Remineralization After Treatment with Four Different Remineralizing Agents: A Scanning Electron Microscopy (SEM) Study. J Clinical and Diagnostic Res. 2017; 4: ZC136-ZC141.

22. Nam I H, Kim M Y. Fluorinated Bioactive Glass Nanoparticles: Enamel Demineralization Prevention and Antibacterial Effect of Orthodontic Bonding Resin. Materials (Basel). 2019; 12: 1813.

23. Onwubu S C, Mdluli P S, Singh S, Nyembe S, Thakur R. An In Situ Evaluation of the Protective Effect of Nano Eggshell/Titanium Dioxide against Erosive Acids. Inter J Dent. 2018; 12: 1-8

24. Yaberi M, Haghgoo R. A comparative study of the effect of nanohydroxyapatite and eggshell on erosive lesions of the enamel of permanent teeth following soft drink exposure: A randomized clinical trial. J Int Oral Health. 2018; 10: 176-9.

25. Taher H M and Bayoumi R E. Remineralization of initial enamel-like lesions with chicken eggshell powder solution versus amorphous calcium phosphate. E D J. 2018; 64: $3703-12$.

26. Feroz S, Moeen F. Protective effect of two different remineralizing agents on artificially induced dental erosion in permanent and primary teeth. Pakistan Oral Dent J. 2018; 37: $657-66$

27. Ávila D M S et al., Influence of bioadhesive polymers on the protective effect of fluoride against erosion. J Dent. 2016; 10: 1-8.

28. Elgamily H, Safy R, Makharita R. Influence of Medicinal Plant Extracts on the Growth of Oral Pathogens Streptococcus Mutans and Lactobacillus Acidophilus: An In-Vitro Study. Open Access Maced J Med Sci. 2019; 7: $2328-34$

29. Salaha M, Kataiab M, Kataiac E, El Dinb A, and Essad M. Evaluation of eggshell powder as an experimental direct pulp capping material. Future Dent J. 2018; 4: 160-4. 